\title{
A IMIGRAÇÃO NO BRASIL CONTEMPORÂNEO: AS REDES DE SOCIABILIDADE E APOIO NA CIDADE DE SÃO PAULO
}

CONTEMPORARY IMMIGRATION: THE NETWORKS OF SOCIABILITY AND SUPPORT IN THE CITY OF SÃO PAULO

\author{
Nina Britto', Maria Amelia Corá2, Myrt Thania Souza ${ }^{3}$
}

RECEBIDO EM: 08/03/2017 / APROVADO EM: 06/06/2017

DOI: $10.5902 / 2317175826077$

\section{RESUMO}

Este trabalho tem por objetivo colaborar para o entendimento do fenômeno das migrações humanas, bem como das redes e das etapas dos processos de acolhimento de imigrantes na cidade de São Paulo, analisando brevemente o papel desempenhado por organizações da sociedade civil. Para isso, pesquisaram-se quais são as características atuais do fenômeno no território brasileiro. Por fim, realizou-se um trabalho de campo em que foram entrevistados 14 estrangeiros, sendo nove imigrantes e cinco refugiados, a partir do qual foi possível traçar algumas redes de apoio e identificar maneiras pelas quais são construídas relações com indivíduos, famílias e instituições. Concluímos que as organizações da sociedade civil desempenham um importante papel na socialização e assistência tanto do refugiado em situação de vulnerabilidade social quanto do imigrante de altos estratos socioeconômicos, na sua fixação na cidade de São Paulo. Outros fatores relevantes identificados foram: os laços familiares, a condição socioeconômica prévia à chegada e as redes de compatriotas, oportunidades nas quais os sujeitos podem recriar suas identidades sociais e os sentimentos de pertença, conforme adesão da análise discursiva proposta por Fairclough.

Palavras-chave: imigração; territórios identitários, redes de pertencimento, São Paulo, deslocamento.

\footnotetext{
1 Especialista em Gestão de Projetos do Terceiro Setor PUC-SP. E-mail: ninamariabritto@gmail.com 2 Profa. Dra. departamento de Administração PUC-SP. E-mail: Profa. Dra. departamento de Administração PUC-SP. E-mail: mel_cora@hotmail.com.

3 Profa. Dra. departamento de Administração PUC-SP. E-mail: myrt@pucsp.br.
} 
A IMIGRAÇÃO NO BRASIL CONTEMPORÂNEO:

AS REDES DE SOCIABILIDADE E APOIO NA CIDADE DE SÃO PAULO

\begin{abstract}
The goal of this research is to contribute to the understanding of the local reception of immigrants and stages of integration in the city of São Paulo. A brief analysis of the role of civil society organizations in this context was made. By doing a fieldwork in which we interviewed nine immigrants and five refugees, it was possible to find out about support networks and how the interviewees built relations with Brazilian individuals, families and institutions. As a result, we found that civil society organizations play an important role in socializing and assisting both socially vulnerable refugees and high income immigrants in settling down in the city of São Paulo. Other significant factors identified were: family links, the socioeconomic situation previous to arrival and the compatriots networks, opportunities in which the individuals are able to recreate their social identities and the feeling of belonging, according to Fairclough's discoursive analysis.
\end{abstract}

Keywords: immigration; Identity territories, belonging networks, São Paulo, Displacement.

\title{
1 Introdução
}

A temática de imigração em um país como o Brasil não é algo recente, porém esse fenômeno vem experimentando, de forma considerável, variadas mudanças ao longo dos últimos anos. De um lado, observa-se que os meios de comunicação apresentam o crescente número de imigrantes com tons de alarmismo, como uma verdadeira "invasão" de haitianos, angolanos, nigerianos e outros estrangeiros pobres que vieram com a intenção de "roubar os empregos" dos brasileiros e sobrecarregar os serviços públicos, demonstrando, dessa maneira, que há um desconhecimento da diferença entre imigrantes e refugiados, em razão da falta de informação sobre as legislações que dão suporte aos refugiados. Por outro lado, essa mesma mídia aborda de forma completamente oposta a vinda de europeus e norte-americanos altamente qualificados para ocupar postos na alta gestão de empresas ou para apostar em novas oportunidades de negócios.

Esses diversos grupos demonstram a complexidade de compreender como tais imigrantes ingressam no Brasil e se organizam para garantir sua permanência de forma a se integrarem econômica, social e culturalmente. Diante disso, esta pesquisa parte das seguintes questões: qual é o caminho trilhado pelos imigrantes para prover sua permanência legalizada, sua subsistência e seu recomeço? Quais são as instituições que os apoiam? Qual é a natureza dessas instituições? Quais são os atores que compõem a rede de acolhimento?

O objetivo geral desta pesquisa consiste, assim, em compreender quais são as redes utilizadas pelos imigrantes para se inserirem de forma econômica e social em São Paulo. Já os objetivos específicos são efetuar o levantamento das motivações e das redes sociais que incorporam os imigrantes na cidade.

Como metodologia, foram realizadas entrevistas em profundidade, de forma presencial e por Skype, com imigrantes que moram ou já moraram em 
São Paulo. Foram entrevistados uma japonesa, dois franceses, um irlandês, um nepalês, um paquistanês, um zimbabuense, um costa-marfinense, uma indiana, um marroquino, uma canadense, um argentino e dois congoleses.

Com base nos dados coletados nas entrevistas, em um primeiro momento, escreve-se, neste estudo, o perfil dos entrevistados, expondo suas motivações e seus vínculos atuais de trabalho e relacionamento. Em seguida, as entrevistas são analisadas por meio da técnica de análise de discurso, procurando contribuir para melhor entendimento sobre a rede de apoio e acolhida do imigrante na cidade de São Paulo. A adoção da análise de discurso proposta por Fairclough (2001, p. 58) parte do pressuposto de que "o discurso é socialmente construído constituindo os sujeitos sociais, as relações sociais e os sistemas de conhecimento e crença".

Dessa maneira, o discurso ultrapassa o texto explícito, sendo uma forma de representar o mundo material (processos, relações e estruturas) e o mundo mental (pensamentos, sentimentos e crenças), originada na posição que o indivíduo ocupa no mundo, em sua identidade social e pessoal e nas relações que estabelece com outras pessoas. $O$ discurso também é considerado ação social, visto que as pessoas podem agir sobre o mundo e sobre os outros a partir de seus discursos. Fairclough (2001) aponta três aspectos dos efeitos construtivos do discurso: construção de identidades sociais, construção das relações sociais entre as pessoas e construção de conhecimentos e crenças.

Spink (2010, p. 27) desenvolve um modelo de análise das práticas discursivas baseado na seguinte definição: "são as maneiras pelas quais as pessoas, por meio da linguagem, produzem sentidos e posicionam-se em relações sociais cotidianas". Para o autor, o processo de pesquisa não consiste em achar o real ou uma investigação para descobrir a verdade, mas, ao contrário, em confrontar, entrecruzar e ampliar os saberes, buscando meios e formas de narrar e veicular nossos estudos que incluam ao invés de excluir; que apoiem os debates ao invés de afastar ou excluir os debatedores (SPINK, 2003, p. 41).

Este artigo apresenta, assim, um referencial teórico, fazendo um traçado acerca das migrações do século XXI no Brasil, seguido da apresentação das redes de integração e seus paradoxos, tentando demonstrar as diferenças entre imigrantes e refugiados. Por último, efetua-se a sistematização das entrevistas realizadas e expõem-se as considerações finais.

\section{Brasil no contexto das migrações do século XXI}

A partir dos anos 1980, o Brasil passou a se inserir no contexto das migrações internacionais como um importante país de fluxos migratórios: de emigrantes e imigrantes. Em 1982, o Alto Comissariado das Nações Unidas para Refugiados (ACNUR) foi oficialmente aceito no Brasil, e, no ano seguinte, o governo brasileiro criou o Conselho Nacional de Imigração, por meio da edição da Resolução n. ${ }^{17}$, "instrumento por meio do qual foram recebidos, não 
A IMIGRAÇÃO NO BRASIL CONTEMPORÂNEO:

como refugiados, mas como estrangeiros temporários, diversos paraguaios, chilenos e argentinos" (BARRETO, 2010, p. 204).

O Brasil é signatário da maior parte dos tratados internacionais de direitos humanos. Em 23 de julho de 1997, entrou em vigor a Lei $n .^{\circ}$ 9.474, regulando as matérias de refúgio. Elaborada no âmbito do Ministério da Justiça, com a ampla participação do ACNUR, essa lei inclui mecanismos de proteção presentes na Convenção de Genebra e no Protocolo de 1967.

Em 1998, a Lei n. ${ }^{\circ} 7.685$ de 1988, que trata da imigração ilegal, foi complementada por uma nova Lei de Anistia (Lei n. ${ }^{\circ}$ 9.675). Durante 90 dias, cerca de 40 mil estrangeiros receberam permissão de residência temporária prorrogável, para aqueles que cumprissem o requisito para residente permanente. Os maiores beneficiários foram bolivianos, chineses e libaneses, embora centenas de sulcoreanos, peruanos, uruguaios e argentinos também tenham sido beneficiadas.

Segundo o Comitê Nacional para os Refugiados (CONARE), em abril de 2014 havia 5.208 refugiados no Brasil, originários de 79 países, sendo $78 \%$ dos refugiados provenientes de países africanos. Os países de origem que mais contribuíram para esse índice são Angola, Colômbia e República Democrática do Congo. Entre 650 e 700 requerimentos são protocolados no país a cada ano, sendo o CONARE o órgão responsável pela decisão de conceder ou negar asilo.

Dados do ACNUR (2014) indicam que o perfil dos refugiados no Brasil é composto de $96 \%$ de adultos e $4 \%$ de crianças; $90 \%$ de homens e $10 \%$ de muIheres. Os países de origem que mais apresentaram pedidos de refúgio foram Síria (com total de 1.524 pedidos); Colômbia (1.218); Angola (1.068); República Democrática do Congo (784); Líbano (391); Palestina (263); Libéria (258); Iraque (229); Bolívia (145) e Serra Leoa (137). Nessa lista, não são contabilizados os haitianos, que recebem visto humanitário, entrando, portanto, na categoria de socorro às vítimas, em virtude do terremoto que destruiu o país em 2010. O crescimento proporcional de entrada de haitianos foi de $406 \%$ entre 2011 e 2012 e de $214 \%$ nos anos de 2012 a 2013 . Levando em conta as quantidades consolidadas (homens e mulheres) de estrangeiros para cada ano, os haitianos passam a ocupar o primeiro lugar de estrangeiros no Brasil pela primeira vez no ano de 2013 (CAVALCANTI; OLIVEIRA; TONHATI, 2015).

No âmbito regional, a lista é encabeçada por dois grupos de imigrantes: os trabalhadores sem papéis fronteiriços e os oriundos dos conflitos armados na Colômbia. Estima-se que cerca de duas mil pessoas por ano cruzem as fronteiras na região Norte do Brasil.

Apesar de o Brasil ter recebido um pequeno número de refugiados - em comparação com outros países -, o ACNUR considera sua política para refúgio exemplar. Isso porque a Lei do Refúgio observa a Declaração de Cartagena, de 1984, que amplia as razões possíveis para que se possa requerer asilo para além daquelas contidas na Convenção de Genebra. Inclui, assim, razões de "violação generalizada dos direitos humanos", como, por exemplo, os conflitos armados, como motivo legítimo para concessão de asilo, bem como per- 
seguições relacionadas ao gênero. Dessa forma, cerca de $11 \%$ dos reconhecimentos de refúgio entre 2005 e 2007 foram concedidos sob a categoria de "mulheres em risco".

Outro mecanismo tido como exemplar é o procedimento de "emergência", do qual se beneficiaram cerca de $4 \%$ dos refugiados. Por meio dele, o reconhecimento se dá em até 72 horas quando há riscos elevados de vida. Segundo a lei, os refugiados reconhecidos oficialmente que habitarem no país por pelo menos seis anos podem requisitar a residência permanente e ter acesso garantido aos serviços públicos.

\section{Paradoxos das redes de acolhimento: a condição de imigrante e refugiado}

O Brasil, como sociedade que acolhe, tem demonstrado pouca propriedade no enfrentamento das questões decorrentes desse acolhimento, o que é evidenciado por meio das redes de integração e dos mecanismos de inserção dos imigrantes e refugiados. De acordo com Sayad (1998), a imigração está diretamente relacionada com o trabalho, e o imigrante "é essencialmente força de trabalho provisória [...], temporária, em trânsito". Portanto, o trabalho faz nascer o imigrante, de modo que, se o trabalho morre, morre também o imigrante, passando a viver um estado de não ser. Porém, no Brasil, a realidade expõe a gradação de tratamento diferenciado e acolhedor para o imigrante que aqui aporta, sob condições econômicas e intelectuais vantajosas, a exemplo de executivos, etnias brancas e detentoras de recursos financeiros. Estabelecem-se condições de acesso diferentes para os grupos de etnias negras, pobres e imigrantes econômicos que buscam a sobrevivência financeira, de forma que a variável trabalho se configura como o recorte preponderante para a condição favorável ou desfavorável para a acolhida e, consequentemente, para as redes informais e formais de integração.

Como argumenta Sayad (1998), o imigrante é um "ser provisório", alguém que está esperando, aguardando; sua situação está sempre em suspensão, o que diferencia as estratégias de integração que se efetivam daquelas que são criadas pelo poder público, mas que, por desconhecer a natureza dos deslocamentos humanos e suas razões de ser, tornam-se pouco eficazes.

Gusmão (2011, p. 197), em seus estudos sobre os estudantes africanos no Brasil, afirma que "presença e invisibilidade constituem-se como faces de uma mesma realidade que tem por contexto o estar fora de lugar, ser africano, ser negro e viver a diáspora 'na terra dos outros'". Assim, alguns grupos encontram mais dificuldade para consolidar as redes de integração, por mais que as entidades de acolhimento trabalhem incessantemente para apoiá-los.

A dinâmica migratória possui peculiaridades de acordo com a etnia, as razões e as motivações dos imigrantes, bem como com as próprias condições 
A IMIGRAÇÃO NO BRASIL CONTEMPORÂNEO:

do deslocamento. Falar em redes de integração no contexto migratório implica trabalhar redes de compatriotas que auxiliam a maximizar o apoio psicológico, logístico, linguístico e financeiro. Porém, é preciso ampliar a noção de redes, na concepção de Castells (1999), entendendo-as como estruturas abertas, capazes de se expandir de forma ilimitada, integrando novos atores, agentes e instituições. Isso inclui redes no âmbito das políticas públicas, redes formais, redes de organismos sociais, entidades religiosas e assistenciais e redes informais, potencializadas pelas redes sociais e mediadas pelo uso da tecnologia. As redes de políticas públicas funcionam como "mecanismos de mobilização de recursos políticos em situações em que a capacidade de tomada de decisão, de formulação e de implementação de programas é amplamente distribuída ou dispersa entre atores públicos e privados" (SCHNEIDER, 2005, p. 40).

Assim, as redes têm sido consideradas uma solução viável e adequada para administrar políticas e projetos em que recursos são escassos e os problemas são complexos e difíceis de serem solucionados, como é o caso da situação dos imigrantes e refugiados na cidade de São Paulo (TEIXEIRA, 2002).

\section{Mapeamento das redes e etapas do processo de acolhimento de imigrantes e refugiados em São Paulo: marginalizados e não marginalizados}

\subsection{Perfil dos entrevistados}

Dos 14 entrevistados, dez têm idades entre 25 e 35 anos, sendo que dois dos refugiados chegaram ao Brasil com 21 anos. Os outros dois refugiados e dois imigrantes têm idade entre 36 e 44 anos.

Em nossa amostra, tivemos quatro mulheres e dez homens. O principal motivo para a escolha desse número de mulheres e homens foi a predominância do gênero masculino entre os alunos da escola e também entre os beneficiários das Organizações não Governamentais (ONGs) Casa do Migrante e Instituto de Reintegração do Refugiado - Adus.

Das quatro imigrantes entrevistadas, três são casadas ou têm relacionamento com homens brasileiros, e apenas uma tem relacionamento com um não brasileiro. Dos dez homens imigrantes entrevistados, quatro são casados ou têm relacionamento com mulheres brasileiras, quatro são casados com muIheres de mesma origem, e dois não estão em relacionamento.

O imigrante entrevistado que está há mais tempo no Brasil é casado com uma brasileira e tem dois filhos brasileiros. Três refugiados casados chegaram ao país sem seus cônjuges e eventualmente conseguiram que eles viessem morar no Brasil. Há um caso de família ainda separada, com um total de duas filhas que se encontram em países africanos, distantes dos pais. 
Notamos, também, que três dos cinco refugiados possuem ensino superior, adquirido em seus países de origem, e que um está cursando uma segunda graduação no Brasil. Apesar disso, apenas um exerce atualmente trabalho que exige formação em nível superior; os outros dois precisaram se adaptar a um ofício de nível técnico, expressando, no entanto, grande interesse em atuar em sua área profissional original.

Dentre os nove imigrantes fora da vulnerabilidade social, todos apresentam ensino superior, e três possuem pós-graduação completa. Com a exceção de uma empreendedora, todos têm interesse em atuar em suas áreas profissionais originárias em São Paulo, embora apenas quatro o façam (Quadro 1).

Quadro 1 - Perfil dos estrangeiros entrevistados

\begin{tabular}{|c|c|c|c|c|c|c|}
\hline Nome & $\begin{array}{l}\text { País de ori- } \\
\text { gem }\end{array}$ & Idade & $\begin{array}{l}\text { Formação edu- } \\
\text { cacional }\end{array}$ & Relacionamento & $\begin{array}{l}\text { Motivo do desloca- } \\
\text { mento }\end{array}$ & $\begin{array}{l}\text { Acesso às redes de integra- } \\
\text { ção da cidade de São Paulo }\end{array}$ \\
\hline Mayuko & Japão & $\begin{array}{c}30 \\
\text { anos }\end{array}$ & $\begin{array}{l}\text { Superior em } \\
\text { Contabilidade }\end{array}$ & $\begin{array}{l}\text { Namorado brasileiro, } \\
\text { sem filhos }\end{array}$ & $\begin{array}{l}\text { Continuar o relacio- } \\
\text { namento amoroso e } \\
\text { estudar. }\end{array}$ & $\begin{array}{l}\text { Escola de Português para } \\
\text { estrangeiros; comunidades } \\
\text { nipônica e nipo-brasileira } \\
\text { de São Paulo; } \\
\text { família e amigos do na- } \\
\text { morado. }\end{array}$ \\
\hline Mathias & França & $\begin{array}{c}28 \\
\text { anos }\end{array}$ & $\begin{array}{l}\text { Superior em } \\
\text { Arquitetura }\end{array}$ & $\begin{array}{l}\text { Namorada brasileira, } \\
\text { sem filhos }\end{array}$ & $\begin{array}{l}\text { Viver uma nova ex- } \\
\text { periência em um país } \\
\text { com imagem atraente; } \\
\text { buscar oportunidades } \\
\text { de trabalho, estudar e } \\
\text { viajar. }\end{array}$ & $\begin{array}{l}\text { Escola de Português para } \\
\text { estrangeiros e de Arquite- } \\
\text { tura; comunidade de fran- } \\
\text { ceses de São Paulo; } \\
\text { família e amigos da na- } \\
\text { morada. }\end{array}$ \\
\hline Stephen & Irlanda & $\begin{array}{c}30 \\
\text { anos }\end{array}$ & $\begin{array}{l}\text { Superior em } \\
\text { Química }\end{array}$ & $\begin{array}{l}\text { Namorada brasileira, } \\
\text { sem filhos }\end{array}$ & $\begin{array}{l}\text { Continuar o relacio- } \\
\text { namento amoroso e } \\
\text { estudar. }\end{array}$ & $\begin{array}{l}\text { Escola de Português para } \\
\text { estrangeiros; } \\
\text { família e amigos da na- } \\
\text { morada. }\end{array}$ \\
\hline Bishwas & Nepal & $\begin{array}{c}25 \\
\text { anos }\end{array}$ & $\begin{array}{l}\text { Superior incom- } \\
\text { pleto }\end{array}$ & $\begin{array}{l}\text { Casado com uma ne- } \\
\text { palesa, sem filhos }\end{array}$ & Buscar refúgio. & $\begin{array}{l}\text { ONGs que atendem } \\
\text { imigrantes e solicitantes } \\
\text { de refúgio em estado de } \\
\text { vulnerabilidade social; } \\
\text { comunidade de nepaleses } \\
\text { e outros refugiados de São } \\
\text { Paulo. }\end{array}$ \\
\hline Adeel & Paquistão & $\begin{array}{c}28 \\
\text { anos }\end{array}$ & $\begin{array}{l}\text { Pós-Graduação } \\
\text { em Finanças }\end{array}$ & Solteiro, sem filhos & $\begin{array}{l}\text { Viver uma nova ex- } \\
\text { periência em um país } \\
\text { com imagem atraente; } \\
\text { buscar melhores oportu- } \\
\text { nidades de trabalho. } \\
\end{array}$ & $\begin{array}{l}\text { Escola de Português para } \\
\text { estrangeiros; mesquita; } \\
\text { academia de ginástica. }\end{array}$ \\
\hline Audrey & França & $\begin{array}{c}32 \\
\text { anos }\end{array}$ & $\begin{array}{l}\text { Superior em } \\
\text { Optometria }\end{array}$ & $\begin{array}{l}\text { Casada com brasilei- } \\
\text { ro, um filho brasileiro }\end{array}$ & Viver com o marido. & $\begin{array}{l}\text { Família e amigos do mari- } \\
\text { do; comunidade de france- } \\
\text { ses de São Paulo; }\end{array}$ \\
\hline George & Zimbábue & $\begin{array}{c}30 \\
\text { anos }\end{array}$ & $\begin{array}{l}\text { Superior em } \\
\text { Comunicação; } \\
\text { cursando Co- } \\
\text { mércio Exterior. }\end{array}$ & $\begin{array}{l}\text { Namorada brasileira, } \\
\text { sem filhos. }\end{array}$ & Buscar refúgio. & $\begin{array}{l}\text { ONGs, que atendem soli- } \\
\text { citantes de refúgio e em } \\
\text { situação de vulnerabilidade } \\
\text { social, faculdade, família da } \\
\text { namorada. }\end{array}$ \\
\hline Desiré & $\begin{array}{l}\text { Costa do } \\
\text { Marfim }\end{array}$ & $\begin{array}{c}25 \\
\text { anos }\end{array}$ & Ensino Médio & $\begin{array}{l}\text { Casado com uma } \\
\text { costa- marfinense, } \\
\text { dois filhos vivendo } \\
\text { ainda na África. }\end{array}$ & Buscar refúgio. & $\begin{array}{l}\text { ONGs que atendem } \\
\text { imigrantes e solicitantes } \\
\text { de refúgio em estado de } \\
\text { vulnerabilidade social; não } \\
\text { revelou outros grupos ou } \\
\text { conexões. }\end{array}$ \\
\hline
\end{tabular}


A IMIGRAÇÃO NO BRASIL CONTEMPORÂNEO:

AS REDES DE SOCIABILIDADE E APOIO NA CIDADE DE SÃO PAULO

\begin{tabular}{|c|c|c|c|c|c|c|}
\hline Saraswati & Índia & $\begin{array}{c}43 \\
\text { anos }\end{array}$ & $\begin{array}{l}\text { Superior em } \\
\text { Farmácia }\end{array}$ & $\begin{array}{l}\text { Casada com um } \\
\text { indiano, um filho } \\
\text { indiano }\end{array}$ & $\begin{array}{l}\text { Assumir cargo elevado } \\
\text { em uma multinacional; } \\
\text { obter promoção na } \\
\text { carreira. }\end{array}$ & $\begin{array}{l}\text { Agência de relocação; } \\
\text { colegas de trabalho; comu- } \\
\text { nidade de expatriados e de } \\
\text { indianos de São Paulo. }\end{array}$ \\
\hline Moulay & Marrocos & $\begin{array}{c}31 \\
\text { anos }\end{array}$ & $\begin{array}{l}\text { Pós-graduação } \\
\text { em Tecnologia } \\
\text { da Informação }\end{array}$ & $\begin{array}{l}\text { Casado com uma } \\
\text { francesa, uma filha } \\
\text { francesa }\end{array}$ & $\begin{array}{l}\text { Acompanhar a esposa } \\
\text { em transferência pela } \\
\text { multinacional; viver uma } \\
\text { nova experiência em } \\
\text { um país com imagem } \\
\text { atraente. }\end{array}$ & $\begin{array}{l}\text { Escola de Português para } \\
\text { estrangeiros; comunidade } \\
\text { de expatriados e de france- } \\
\text { ses de São Paulo; agência } \\
\text { de relocação; iate clube. }\end{array}$ \\
\hline Geneviève & Canadá & $\begin{array}{c}27 \\
\text { anos }\end{array}$ & $\begin{array}{l}\text { Superior em } \\
\text { Educação }\end{array}$ & $\begin{array}{l}\text { Casada com um bra- } \\
\text { sileiro, sem filhos }\end{array}$ & $\begin{array}{l}\text { Viver com o marido; } \\
\text { ajudá-lo no processo de } \\
\text { imigração para o Cana- } \\
\text { dá e trabalhar. }\end{array}$ & $\begin{array}{l}\text { Escola de francês que- } \\
\text { bequense; comunidade } \\
\text { de quebequenses de São } \\
\text { Paulo. }\end{array}$ \\
\hline Sebastián & Argentina & $\begin{array}{c}44 \\
\text { anos }\end{array}$ & $\begin{array}{l}\text { Pós-Graduação } \\
\text { em Economia }\end{array}$ & $\begin{array}{l}\text { Casado com uma } \\
\text { brasileira, dois filhos } \\
\text { brasileiros }\end{array}$ & $\begin{array}{l}\text { Viver com a esposa; } \\
\text { buscar oportunidades } \\
\text { de trabalho. }\end{array}$ & $\begin{array}{l}\text { Familia e amigos da es- } \\
\text { posa; colegas de trabalho; } \\
\text { comunidades de argenti- } \\
\text { nos e de estrangeiros em } \\
\text { geral de São Paulo; clube } \\
\text { desportivo. } \\
\end{array}$ \\
\hline Samuel & $\begin{array}{l}\text { República } \\
\text { Demo- } \\
\text { crática do } \\
\text { Congo }\end{array}$ & $\begin{array}{c}36 \\
\text { anos }\end{array}$ & $\begin{array}{l}\text { Superior em } \\
\text { Contabilidade }\end{array}$ & $\begin{array}{l}\text { Casado com uma } \\
\text { congolesa, um filho } \\
\text { brasileiro }\end{array}$ & Buscar refúgio. & $\begin{array}{l}\text { ONGs que atendem } \\
\text { imigrantes e solicitantes } \\
\text { de refúgio em estado de } \\
\text { vulnerabilidade social; } \\
\text { comunidades de africanos } \\
\text { de São Paulo; igreja evan- } \\
\text { gélica (Campinas); colegas } \\
\text { de trabalho africanos } \\
\text { (Campinas). } \\
\end{array}$ \\
\hline Elvis & $\begin{array}{l}\text { República } \\
\text { Demo- } \\
\text { crática do } \\
\text { Congo }\end{array}$ & $\begin{array}{c}36 \\
\text { anos }\end{array}$ & $\begin{array}{l}\text { Superior em } \\
\text { Contabilidade }\end{array}$ & Solteiro, sem filhos & Buscar refúgio. & $\begin{array}{l}\text { ONGs que atendem } \\
\text { imigrantes e solicitantes } \\
\text { de refúgio em estado de } \\
\text { vulnerabilidade social; } \\
\text { comunidades de africanos } \\
\text { de São Paulo; igreja evan- } \\
\text { gélica (Campinas); colegas } \\
\text { de trabalho africanos } \\
\text { (Campinas). }\end{array}$ \\
\hline
\end{tabular}

Fonte: elaboração própria.

É interessante notar que seis dos 14 entrevistados já haviam conhecido o Brasil como turista e que quatro dos cinco refugiados não tinham consciência de que seu destino seria esse país. Destes, dois acreditavam que estavam indo para os Estados Unidos, porém "foram deixados aqui" pelos intermediadores. Apenas um refugiado afirma ter escolhido o Brasil deliberadamente como país para viver.

Comparando o grupo dos refugiados com o dos imigrantes, notamos que há uma grande diferença quanto à escolha do Brasil, uma vez que os imigrantes escolheram o país, seja por motivos familiares ou por terem uma percepção positiva do país e uma experiência como turista, enquanto que a maioria dos refugiados entrevistados afirma ter a preferência pelos Estados Unidos ou outro país.

Compreender o perfil dos entrevistados auxilia a entender como são as relações traçadas entre os imigrantes e refugiados na construção de uma identidade com o novo país de morada. Esses sujeitos passam pela busca de aprender um idioma que garanta a comunicação e, com isso, a produção de 
sentidos e posicionamentos das relações sociais nesse novo cotidiano em que estão inseridos. Assim, a análise das práticas discursivas das falas dos entrevistados permite compreendê-los enquanto linguagens em ação, ou seja, como sujeitos históricos em busca de reconstruir seus processos identitários.

\subsection{0 processo de emissão de visto}

Dentre os 14 entrevistados, somente dois têm visto de turista; um, de estudante; e um, de trabalho. Um dos estrangeiros está há cerca de quatro anos no Brasil apenas com o protocolo da solicitação do Registro Nacional de Estrangeiro (RNE), emitido pela Polícia Federal, vivendo em um limbo jurídico que amplia sua vulnerabilidade social, pois ainda não possui o status de refugiado legalmente reconhecido. Os demais possuem visto permanente ou o RNE, sendo dois deles por reunião familiar.

Quando perguntados se buscaram algum tipo de auxílio para a obtenção do visto, apenas os dois imigrantes com visto de turismo e uma com visto permanente afirmaram ter feito o processo completamente sozinhos. Todos os demais disseram ter buscado ajuda de alguma organização ou algum profissional especializado. Dentre os profissionais citados, estão dois escritórios de advocacia, um escritório de despachante e duas agências de relocação. Todos os refugiados deram entrada em seu pedido de regularização por meio da ONG Cáritas Arquidiocesana de São Paulo. O solicitante que ainda não obteve resposta do governo afirma que não está mais recebendo ajuda da ONG nessa questão e que não tem mais a quem recorrer.

Dois entrevistados disseram ter recebido ajuda e orientação das comunidades de franceses e quebequenses de São Paulo sobre como proceder para a obtenção de seus vistos. Os dois imigrantes que foram atendidos pelas agências de relocação afirmaram que as empresas se ocuparam da maior parte das necessidades iniciais de sua fixação na cidade, tais como encontrar apartamento para alugar, matricular os filhos nas escolas internacionais e obter CPF, carteira de habilitação e vistos.

Quadro 2 - Comparativo dos tipos de visto, documentação e agentes envolvidos

\begin{tabular}{|l|l|}
\hline Imigrantes & Refugiados \\
\hline Visto de Turismo & $\begin{array}{l}\text { Protocolo de solicitação de RNE, status de refugiado ainda não } \\
\text { reconhecido }\end{array}$ \\
\hline Visto de estudo & RNE, status de refugiado reconhecido \\
\hline Visto de trabalho & $\begin{array}{l}\text { Beneficiários dos serviços jurídicos de regularização de permanência } \\
\text { da ONG Cáritas Arquidiocesana de São Paulo }\end{array}$ \\
\hline Visto de residência permanente & \\
\hline RNE & \\
\hline $\begin{array}{l}\text { Serviços contratados: escritórios de advocacia, despachante } \\
\text { e agência de relocação }\end{array}$ & \\
\hline Orientação das comunidades de franceses e quebequenses & \\
\hline Fonte: elaboração própria.
\end{tabular}

Fonte: elaboração própria. 
A IMIGRAÇÃO NO BRASIL CONTEMPORÂNEO:

Quanto à obtenção do visto e às dificuldades para isso, as queixas mais comuns são o excesso de documentação exigida, o processo altamente burocratizado e o atendimento precário realizado pela Polícia Federal. Não há informações claras disponíveis no site nem pelo telefone; os atendentes não são capazes de se comunicar em outro idioma que não seja o português; os funcionários não informam sobre mudanças nas leis; há muita fila no local e o tempo de espera pelo atendimento é longo; e os atendentes demonstram abertamente uma atitude interpretada por alguns entrevistados como de "má vontade".

Nesse sentido, pode-se considerar, com base no discurso dos entrevistados, que fica clara a materialidade dos processos, das relações e das estruturas envolvidos para obtenção dos vistos, já que cada experiência vivenciada pelos entrevistados reitera que a burocracia e o baixo acesso a informações são usados como subterfúgios da dificuldade para adquirir o visto. A fricção entre as materialidades e a busca por construir relações sociais entre pessoas de diferentes culturas impõe desafios para a produção das práticas discursivas que irão subsidiar o alcance das necessidades concretas e abstratas dos refugiados e imigrantes.

As dificuldades com o processo altamente burocratizado também foram citadas pelos entrevistados que se casaram no Brasil. Devido a essas dificuldades, a maior parte teve necessidade de contratar os serviços especializados descritos anteriormente.

Dentre os refugiados, apenas um afirmou não ter tido dificuldades para obter o RNE e seu status jurídico reconhecido. Segundo ele, como sua situação "era grave" e sua história era "verdadeira", dentro de poucos meses obteve os documentos. Para os demais, o processo levou anos ou ainda não foi concluído.

De acordo com um entrevistado, a utilização do protocolo de solicitação de refúgio - documento provisório emitido pela Polícia Federal - gera dúvidas e suspeitas entre os brasileiros, que não o conhecem e passam a desconfiar de sua autenticidade e de seu portador. Em seu caso, o processo de obtenção do RNE levou cerca de 18 meses, dificultando sua recolocação profissional e, portanto, sua inserção socioeconômica. É patente observar a fragilidade e, portanto, a vulnerabilidade a que o solicitante de refúgio está sujeito ao portar por meses e até anos apenas o protocolo da solicitação, que, na prática, é desconhecido pela maior parte dos brasileiros, gerando rejeição e segregação.

O solicitante de refúgio que ainda não obteve seu status reconhecido afirma que o pedido inicial foi negado pelo CONARE, tendo então entrado com recurso, conforme previsto em lei, há cerca de quatro anos. Segundo ele, mesmo com diversos telefonemas para a ONG Cáritas e com diversas idas ao órgão governamental de competência, não tem tido acesso às informações sobre seu processo.

Outro refugiado, que passou pela mesma situação e ainda não tem claramente seu status reconhecido, ressaltou a falta de transparência do processo e das instituições envolvidas. Sem o documento, destaca, não é possível obter acesso a oportunidades educacionais e a outros documentos, como a carteira de habilitação, necessária para o desempenho pleno de sua nova profissão. 
Dessa forma, fica comprometida a reinserção socioeconômica, e pereniza-se o estado de vulnerabilidade social a que estão sujeitos.

4.3 Redes e fixação dos imigrantes e refugiados na cidade de São Paulo

Foram feitas quatro questões relacionadas às redes de apoio e fixação criadas ou usadas pelos imigrantes e refugiados primordialmente na cidade de São Paulo, e, secundariamente, em Belo Horizonte, Campinas e Salvador. Essas questões tinham como propósito analisar a construção das relações sociais entre as pessoas e consequentemente as identidades sociais e culturais constituídas durante esse processo.

Os imigrantes citaram como organizações de apoio para sua fixação na cidade principalmente empresas privadas e redes informais, tais como a escola de português para estrangeiros, a comunidade francesa de São Paulo e agências de relocação. É interessante notar que a escola de português foi citada por cinco entrevistados como um local de socialização, onde é possível conhecer outros estrangeiros em situação similar e realizar o intercâmbio de informações, assim como os professores brasileiros, que, além de ensinarem o idioma, compartilham aspectos da cultura.

Uma escola de arquitetura também foi citada como local de constituição de redes e contato com brasileiros em sua área de formação, com a possibilidade eventual de uma colocação profissional. Uma academia de ginástica foi citada uma vez, como local para novos contatos e eventuais amizades; e o curso de português para estrangeiros da Pontifícia Universidade Católica de São Paulo (PUC-SP) foi citado por um entrevistado.

As agências de relocação foram citadas por dois entrevistados e receberam reconhecimento como agentes facilitadores de necessidades práticas e primárias dos imigrantes. É importante salientar que os imigrantes entrevistados não arcaram com os custos da contratação, pois os serviços de tais agências eram oferecidos pelas empresas empregadoras, dentro do contexto da transferência internacional do funcionário.

Três entrevistados fizeram referência a uma rede informal constituída de franceses residentes na cidade de São Paulo. Segundo os relatos, trata-se de um grupo de pessoas que se reúne em eventos nas casas uns dos outros e em cafés, com a finalidade de conversar, trocar informações e fazer contatos profissionais. O grupo organiza-se, ainda, para fazer turismo e jogar futebol.

Os consulados da França e da Argentina foram citados uma vez cada um, como um dos locais procurados para obter informações e fazer networking. No caso do entrevistado argentino, sua inserção profissional ocorreu por meio do consulado, após passar alguns meses desempregado em São Paulo. Ele atua há mais de uma década no departamento de promoção comercial do Consulado Geral da República Argentina. 
A IMIGRAÇÃO NO BRASIL CONTEMPORÂNEO:

Houve apenas um entrevistado do grupo dos imigrantes que citou um local religioso como espaço de inserção social. $O$ entrevistado paquistanês informou que, para a prática religiosa, frequenta uma mesquita em São Paulo, ampliando, dessa maneira, sua rede de relacionamentos.

Um clube desportivo e um de iatismo foram citados uma vez cada um como locais de socialização. Um torneio de futebol conhecido como Copa Gringos foi referido por três entrevistados.

A executiva indiana fez referência a um serviço de consultoria na área de coaching cultural, oferecido pela empresa empregadora aos diretores estrangeiros, para que possam discutir e entender a cultura brasileira e o modo de trabalho no país. Já a escola de francês École Québec foi citada pela canadense como local de convivência com seus conterrâneos e troca de informações práticas sobre a vida no Brasil. Essa escola foi fundada por uma imigrante originária da província do Quebec, Canadá, há cerca de dez anos e funciona como um centro de referência para os quebequenses que vivem na cidade. Como seus conterrâneos com maior tempo de experiência na cidade formaram uma sólida rede de apoio local, a partir dessa convivência foi possível fazer os arranjos para o aluguel de seu apartamento, dentre outras medidas práticas.

Houve referência a algumas organizações da sociedade civil entre os imigrantes francófonos, tais como as associações civis ligadas à comunidade francesa My Little Brasil e São Paulo Accueil, que atuam construindo redes entre seus conterrâneos residentes na cidade de São Paulo. Os dois entrevistados que citaram essas organizações dizem que as utilizam para fazer contatos comerciais e passeios.

A entrevistada canadense também citou uma organização da sociedade civil como vínculo inicial no Brasil. Ela veio a princípio por meio da ONG canadense Centre Solidarité Corcovado realizar um trabalho voluntário humanitário junto a uma ONG parceira de Salvador, na Bahia. Nessa cidade, ela ampliou seu círculo de amizades, conhecendo alguns brasileiros, dentre os quais estava seu atual marido.

É importante notar o papel fundamental que exercem os laços familiares com brasileiros na inserção em uma nova cidade e um novo país. A rede formada pelo relacionamento com cônjuges ou namorados brasileiros e suas famílias é citada por sete entrevistados. A entrevistada japonesa afirma que é seu marido quem a apresenta a novos brasileiros e à comunidade japonesa da cidade, além de ajudá-la a procurar um emprego. A reunião familiar foi também a principal razão para a vinda dos entrevistados argentino, francesa, canadense e irlandês, de forma que a família se apresentou como o principal eixo para a integração inicial desses imigrantes.

Há, ainda, dois dos entrevistados que vieram para o Brasil sem ter relacionamento com brasileiras, mas atualmente estão em um relacionamento, o que estreita os laços com o país.

Dentre os refugiados, foram citadas três organizações da sociedade civil como apoio inicial na cidade de São Paulo: Cáritas Arquidiocesana de São Paulo (apoio à regularização documental), Missão Paz-Casa do Migrante (abri- 
go, banho e alimentação duas vezes ao dia, espaço de convivência) e Adus Instituto de Reintegração do Refugiado Brasil (procura de emprego e espaço de convívio). Todos os cinco refugiados receberam apoio das duas primeiras ONGs, e um recebeu também apoio da última ONG citada.

O refugiado nepalês conheceu outros conterrâneos na cidade de São Paulo e, por meio deles, começou a atuar como vendedor ambulante na Rua 25 de Março e na Feira do Brás. Posteriormente, um desses contatos o indicou para um trabalho como garçom na cidade de Belo Horizonte, para onde se mudou. Ainda na cidade de São Paulo, conheceu alguns brasileiros voluntários da Casa do Migrante, que, segundo ele, foram de grande ajuda, pois podiam se comunicar em inglês e dar-lhe algumas orientações. Em Belo Horizonte, contou com a confiança de uma família de brasileiros, que o apoiou e the ofereceu um emprego em um restaurante. Posteriormente, conseguiu um emprego com registro formal como vendedor em uma loja, onde atua há três anos. Vem aprendendo a língua portuguesa na prática do dia a dia sem nunca ter frequentado uma escola. Um espaço que frequenta em suas horas de lazer é o Serviço Social do Comércio (SESC) de Belo Horizonte.

Além de inicialmente ter recebido ajuda das ONGs Casa do Migrante e Cáritas, o refugiado zimbabuense citou como redes de apoio a universidade onde cursa sua segunda graduação, os colegas de trabalho das escolas de inglês em que atua, a namorada brasileira e sua família e duas ONGs nas quais atuou como voluntário: a Oxfam International e a Associação Afro Brasil. É interessante notar que ele já havia trabalhado na Oxfam International em seu país de origem.

O refugiado costa-marfinense começou um curso técnico na instituição Serviço Nacional de Aprendizagem Industrial (SENAI), sem, porém, concluí-lo. Ele foi evasivo em suas respostas sobre sua rede de contatos, questionando a pergunta e não revelando os grupos nos quais circula. Não foi possível saber qual é atualmente sua fonte de renda, e ele preferiu fazer a entrevista em francês, de forma que não sabemos qual é seu grau de integração linguístico.

Os refugiados congoleses também estão aprendendo a língua portuguesa em sua prática cotidiana, sem terem frequentado uma escola. Após oito meses em São Paulo, conseguiram alguns trabalhos informais, sendo mais tarde indicados por um conhecido para trabalhar como gesseiros na cidade de Campinas. Ambos se mudaram para lá e, com o apoio de outros refugiados africanos, aprenderam a nova profissão, nela atuando por três anos. Atualmente, no entanto, estão desempregados, pois, segundo informaram, não possuem mais o veículo que usavam para atender os clientes (pertencia aos amigos que não moram mais na cidade). Eles citam uma igreja evangélica como local de convívio, onde podem conhecer outros brasileiros. Entretanto, um deles ressalta que ainda não tem muitos amigos locais, achando difícil começar contatos.

A ferramenta de comunicação digital Facebook foi citada como local de encontros virtuais e intercâmbio de informações entre os franceses - Comunidade Franceses de São Paulo - e entre estrangeiros no geral - Comunidade Gringos 
A IMIGRAÇÃO NO BRASIL CONTEMPORÂNEO:

-, bem como entre estrangeiros e brasileiros. De acordo com os entrevistados, as comunidades são espaços frequentemente utilizados por eles, tendo sido citadas por três: dois franceses e um marroquino. Os contatos dos imigrantes com brasileiros realizados pessoalmente também são mantidos por meio da mídia.

Outras redes virtuais citadas foram a InterNation, rede paga e exclusiva para trabalhadores imigrantes temporários transferidos pelas empresas (conhecidos como expatriados ou expats), o Linkedln e o Meet-Up. Por meio delas, organizam-se festas e faz-se networking para finalidades pessoais e profissionais.

\section{Considerações finais}

A partir desta pesquisa, pudemos observar que o tema das migrações contemporâneas está na pauta do dia dos estados, nas esferas legislativa e executiva, dos poderes públicos federal, estadual, municipal e internacional, assim como na iniciativa privada e no terceiro setor. Por ser um fenômeno de múltiplos aspectos, com características sociais, econômicas, culturais, políticas, jurídicas e identitárias, a migração - e particularmente a imigração, como estudada neste trabalho - deve necessariamente ser abordada por diversos órgãos, especialidades e campos de estudo.

Pudemos notar, ao longo do trabalho, que, na cidade de São Paulo, diversos atores contribuem para o acolhimento do imigrante, sua permanência legalizada, sua reinserção socioeconômica e seu recomeço. De acordo com o que foi pesquisado, a participação das organizações da sociedade civil de assistência social é de grande importância no acolhimento do imigrante forçado, isto é, do refugiado, diferentemente do que ocorre com os imigrantes econômicos que se encontram fora da vulnerabilidade social.

No entanto, descobrimos que também esses imigrantes com melhor acesso a recursos para integração socioeconômica são beneficiários de organizações da sociedade civil, especificamente de duas ONGs que atuam na e para a comunidade de franceses residentes na cidade de São Paulo, as associações My Little Brasil e São Paulo Accueil.

São de relevante importância também as redes de compatriotas já existentes anteriormente na cidade, com as quais os recém-chegados passam a ter contato, esclarecendo dúvidas acerca da vida prática e da burocracia que envolve as várias etapas para sua permanência no país. Isso parece verdadeiro, de acordo com as entrevistas, tanto para refugiados quanto para imigrantes. Para visibilizar as identidades sociais que estão em constante metamorfose, os participantes da pesquisa produzem sentidos para os desafios que se colocam no seu cotidiano. Assim, buscam construir relações sociais com as pessoas que aqui estão, sem perder de vista a ancoragem nos sentimentos de pertença à história identitária.

Outro eixo fundamental para a inserção social, como pudemos observar, consiste nos laços familiares, que funcionam tanto como motivação inicial para a vinda quanto como apoio psicológico, logístico, linguístico e, às vezes, finan- 
ceiro, para a permanência e reinserção na sociedade. No caso dos entrevistados que estão há mais tempo no Brasil, a formação da família parece conduzir à fixação em caráter permanente no país.

Notamos que alguns fatores parecem ser fundamentais para o recomeço no Brasil: a condição financeira no país de origem, isto é, antes da mudança; a forma como chegou ao Brasil (se por meio da contratação de intermediários, de forma clandestina ou regularizada); o nível educacional obtido antes de chegar ao país e a preexistência de laços familiares com brasileiros.

Quando analisamos um pouco da realidade de alguns imigrantes que vivem no Brasil, é possível observar a diversidade de situações socioeconômicas e jurídicas em que se encontram, com alguns tendo acesso a empregos altamente remunerados e utilizando-se de empresas facilitadoras da vida prática e burocrática, e outros ainda desempregados ou em trabalhos informais, ou vivendo em um limbo jurídico sem resolução, ao longo de anos. A análise das práticas discursivas das pessoas entrevistadas aponta para o posicionamento dos sujeitos frente às identidades sociais e os sentimentos de pertença; a busca por um lugar no mundo; a construção das relações sociais entre as pessoas, em grupos de semelhantes e em espaços com o outro; e a construção de conhecimentos e crenças, conforme adesão da análise discursiva proposta por Fairclough (2001).

Atores da iniciativa privada exercem um papel de importância junto aos imigrantes bem posicionados na pirâmide social, uma vez que as agências de relocação trabalham de maneira a facilitar todos os aspectos práticos da instalação do imigrante e de sua família. Assim, também as escolas de Português como Língua Estrangeira e os professores particulares podem ser incluídos nesse grupo, funcionando como comunidades seletivas de estrangeiros de diversas nacionalidades, que possuem a condição financeira para delas participarem.

Os espaços virtuais também se revelam importantes para a socialização do imigrante, podendo, no entanto, não promover a integração com brasileiros, mas sim o fechamento em grupos e redes exclusivas para imigrantes, ou "expatriados", tais como a rede InterNation.

À guisa de conclusão, podemos afirmar que as situações dos imigrantes no Brasil - e especificamente na cidade de São Paulo - são tão diversas quanto as muitas variáveis pessoais, jurídicas e socioeconômicas envolvidas sugerem. Trata-se de um campo de estudos e de atuação do terceiro setor, do estado e da iniciativa privada em renovada atenção e constante aprimoramento, uma vez que a tendência do fenômeno parece ser sua intensificação para os anos vindouros. No entanto, reconhecemos que são necessários estudos mais aprofundados e específicos que dêem suporte para questões pouco ou nada abordadas neste trabalho, de maneira que seja possível vislumbrar com maior clareza quem são e por onde circulam os imigrantes do século XXI no Brasil. 
A IMIGRAÇÃO NO BRASIL CONTEMPORÂNEO:

AS REDES DE SOCIABILIDADE E APOIO NA CIDADE DE SÃO PAULO

\section{REFERÊNCIAS}

BAENINGER, F. Africanos no Brasil: Dubiedade e Estereótipos. Brasil: Migrações Internacionais e Identidade. ComCiência, 2000. Disponível em: http://www.comciencia.br/reportagens/migracoes/migr11.htm. Acesso em: 20 de mar. 2015.

BARRETO, L. P. T. F. (org.). Refúgio no Brasil: a proteção brasileira aos refugiados e seu impacto nas Américas. Brasília: ACNUR/CONARE: Ministério da Justiça, 2010.

CASTELLS, M. A sociedade em rede. São Paulo: Paz e Terra, 1999.

CAVALCANTI, L.; OLIVEIRA, A. T.; TONHATI, T. (orgs.) A Inserção dos Imigrantes no Mercado de Trabalho Brasileiro. Cadernos OBMigra, Ed. Especial, Brasília, 2015.

COMISSIÓN ECONÓMICA PARA AMÉRICA LATINA Y EL CARIBE. Migración Interna y Desarollo en América Latina y el Caribe. Continuidades, Cambios y Desafíos de Política. Panorama Social de América Latina. CEPAL, 2007: p. 22-25, 2008.

FAIRCLOUGH, N. Discurso e mudança social. Brasília: UNB, 2001.

GUSMÃO, N. M. M. de. "Na Terra do Outro": presença e invisibilidade de estudantes africanos no Brasil, hoje. Dimensões, vol. 26, p. 191-204, 2011.

INSTITUTO BRASILEIRO DE GEOGRAFIA E ESTATÍ́STICA. Dados históricos do Censo - Estimativas da População - 1550-1870. IBGE, Brasil. Disponível em http://www.ibge.gov.br/home/estatistica/populacao/ censohistorico/1550_1870.shtm, Acesso em 07 de abr. 2015.

MINISTÉRIO DAS RELAÇÕES EXTERIORES. Censo IBGE estima brasileiros no exterior em cerca de $\mathbf{5 0 0}$ mil. MRE. Brasília, 2011. Disponível em: http://www.brasileirosnomundo.itamaraty.gov.br/noticias/censo-ibge-estimabrasileiros-no-exterior-em-cerca-de-500-mil/impressao. Acesso em 05 de mai de 2015.

REIS, T. Brasil tem hoje 5,2 mil refugiados de 79 nacionalidades. O Globo, São Paulo, 24 de abril de 2014. Disponível em http://g1.globo.com/mundo/noticia/2014/04/brasil-tem-hoje-52-mil-refugiados-de-79-nacionalidadesdiferentes.html. Acesso em 25 de jun. de 2015.

SAYAD, A. S. Imigração ou os paradoxos da alteridade. São Paulo: Edusp, 1998.

SCHNEIDER, V. Redes de políticas públicas e a condução de sociedades complexas. Civitas, Porto Alegre, v.5, n1, jan/ jun. 2005, p. $29-58$.

SPINK, M. J. Linguagem e Produção de Sentidos no Cotidiano. Rio de Janeiro: Centro Edelstein de Pesquisas Sociais, 2010.

SPINK, P. K. Pesquisa de campo em psicologia social: uma perspectiva pós-construcionista. Psicologia \& Sociedade, v. 15, n. 2 , p. $18-42,2003$.

STELZIG,S. Brazil: Country Profile. Focus Migration. Hamburg Institute of International Economics: Hamburgo, 2008. Disponível em: http://focus-migration.hwwi.de/Brazil.5879.0.html?\&L=1. Acesso em 07 de abr. de 2015.

TEIXEIRA, S. M. F. O desafio da gestão das redes de políticas. Anais ... VII CLAD sobre la Reforma de Estado y de la Administración Pública, Lisboa, 8 a 11 de outubro 2002. 